\title{
Electrophysical properties of Silicon doped by Nickel impurity using Diffusion method
}

\author{
Sharifa Utamuradova ${ }^{1}$, Sayfillo Nasriddinov ${ }^{2}$, Shuhratbek Ismoilov ${ }^{3}$ \\ ${ }^{1}$ Research Institute of Semiconductors and Microelectronics under National University of Uzbekistan, 100057, \\ Tashkent, Uzbekistan, Email: sh-utamuradova@yandex.ru \\ ${ }^{2}$ Research Institute of Semiconductors and Microelectronics under National University of Uzbekistan, 100057, \\ Tashkent, Uzbekistan, Email: sfera3110@yandex.ru \\ ${ }^{3}$ Research Institute of Semiconductors and Microelectronics under National University of Uzbekistan, 100057,
} Tashkent, Uzbekistan, Email: ismoilov-2015@inbox.ru

\begin{abstract}
Silicon is a mature material, but it is still unique for its crucial role in the microelectronic and photovoltaic sectors. Despite the vast knowledge accumulated on silicon and their alloys, this material still demands research. In this paper, the conductivity and lifetime of non equilibrium charge carriers of nickel impurities in single-crystal silicon are determined. The electrophysical properties for the silicon single crystals doped with nickel impurity by establishing optimal diffusion mode were studied with the Hall effect method and the standard method in constant electric and magnetic fields. It is shown that the generation of thermal donors is suppressed by the interaction of nickel and oxygen impurities introduced at $500^{\circ} \mathrm{C}$, and it is proved that it does not affect the formation of high-temperature thermal donors formed at $700^{\circ} \mathrm{C}$.
\end{abstract}

Key words : Chemical deposition, material defect, heat treatment, nickel diffusion, silicon.

\section{INTRODUCTION}

The use of Si: Ni in annealing technology is of great interest to nickel impurities in monocrystalline silicon and their use for the manufacture of thermistors. The widespread use of $\mathrm{Ni}$ as a dopant as an alternative to expensive gold in the production of high-speed highly sensitive structures [1],[2]. Moreover, there are applications of alloying methods in industry, such as laser technology to change processing speed [3], effects of heat transfer on float glass surface [4] and so on. There are various alloys of nickel in silicon. One of them is chemical precipitation. Advantages of this method: use of energy-saving technology; lack of need to apply vacuum equipment; reduction in production costs; obtaining products with new characteristics: multilayer metallization of silicon with a variable nature of metal layers. The most important stage of the technology is the chemical deposition of nickel films from an aqueous hypophosphite solution with the inclusion of a small amount of phosphorus, which provides strong adhesion to silicon, the electrical conductivity of the wafer surface and the possibility of further chemical, electrochemical or contact deposition from solutions of nickel films. Both palladium and palladium activation are used to impart catalytic activity to the silicon surface in the nickel chemical precipitation reaction. To prepare the plates for applying metal films, an silicon etching operation is performed. Technical characteristics of solutions and operating conditions: high-speed alkaline solutions or acidic ones containing fluoride ions are used for silicon etching; for activation before chemical nickel plating, applying from a solution of a palladium catalyst is used or palladium activation is carried out; the duration of the operations of applying each layer of metal or alloy does not exceed 5-7 minutes; all solutions are reusable; the working temperature of the solutions, depending on their purpose, is from 18 to $98^{\circ}$ $\mathrm{C}$; in some cases, between separate operations, washing with water is not required [5]-[7].

The next doping method is those obtained during the formation of nickel silicides by burning a nickel film into a polysilicon film deposited on oxidized single-crystal silicon, that is, by magnetron sputtering. To obtain the required sample by the diffusion method, the silicon wafer was doped with phosphorus, then a nickel film (500 to $1200 \AA$ ) was sprayed onto polysilicon in a vacuum by magnetron sputtering [8].

\section{MATERIALS AND METHODS}

To study the electrophysical properties, n-type and p-type silicon single crystals doped with nickel impurity by diffusion used the Hall effect method and the conductivity was carried out according to the standard method in constant electric and magnetic fields. The optical properties of samples of silicon doped with nickel were studied using spectral instruments of the near and middle IR ranges $(0.75-25 \mu \mathrm{m})$ [1]. A similar work investigated by Y. Pratapa et al [9], where electro-chemical behavior of various metals is studied .In the studies, we used a method used by Fujimoriet.al [10], where single-crystal silicon samples with a dislocation density of $5 \times$ $10^{13} \div 10^{15} \mathrm{~cm}^{-3}$ with an initial concentration of phosphorus impurities. The concentration of IR active oxygen in these samples was $(1 \div 8) 10^{17} \mathrm{~cm}^{-3}$, and carbon $\sim 10^{17} \mathrm{~cm}^{-3}$. Nickel 
was introduced by diffusion at temperatures of $1100 \div 1250^{\circ}$ C. The effect of the temperature of diffusion and low-temperature treatment on the absorption spectrum at room and nitrogen temperatures was investigated. The differential absorption spectrum was recorded relative to the annealed control samples of silicon without nickel. Special attention was paid to plane parallelism and polishing of samples. The thickness of the samples was within $1.5-4 \mathrm{~mm}$. To reveal a correlation between the oxygen and nickel concentrations in silicon, diffusion was carried out at temperatures of $1000-1370^{\circ} \mathrm{C}$, which made it possible to control the concentration of nickel introduced in the range $10^{16} \div 7 \cdot 10^{17} \mathrm{~cm}^{-3}$. The concentration of introduced nickel was determined by the activation method.

\section{EXPERIMENTAL RESULTS}

During diffusion alloying with nickel of crystals with specific resistance $\rho=10-100 \mathrm{Ohm} \cdot \mathrm{cm}$, changes in the electrophysical and optical properties of $\mathrm{Si}\langle\mathrm{Ni}\rangle$ samples during thermal annealing, it was found that nickel creates two acceptor levels with energy $E_{1}=E_{v}+0.2 \mathrm{eV}$ and $E_{2}=E_{c}-0.4 \mathrm{eV}$ at a concentration of nickel introduced $7 \cdot 10^{17} \mathrm{~cm}^{-3}$. Nickel atoms are located mainly in the nodes of the crystal lattice in the form of neutral atoms $\left(\mathrm{Ni}^{\circ}\right)$, singly and doubly charged ions $\left(\mathrm{Ni}^{-}, \mathrm{Ni}^{--}\right)$. The maximum concentration of electroactive atoms is $\mathrm{N}_{\mathrm{Ni}}=4 \cdot 10^{14} \mathrm{~cm}^{-3}$.

Electron-neutral nickel atoms $\left(\mathrm{Ni}^{\mathrm{o}}-3 \mathrm{~d}^{8} 4 \mathrm{~s}^{2}, \quad \mathrm{Ni}^{-} 3 \mathrm{~d}^{5} 4 \mathrm{~s}^{2} 4 \mathrm{p}\right.$, $\mathrm{Ni}^{-} 3 \mathrm{~d}^{8} 4 \mathrm{~s}^{2} 3 \mathrm{p}^{2}$ moving along dislocations form complexes with oxygen of the $\mathrm{NiO}_{\mathrm{x}}$ type, as well as complexes with other defects. After the staged low-temperature diffusion of nickel in the bulk of silicon, nanoclusters of nickel atoms are formed, which are in the $3 \mathrm{~d}^{10}$ state. he formation of $\mathrm{NiO}_{\mathrm{x}}$ complexes by neutral nickel atoms and nanoclusters from electro active nickel atoms in highly compensated silicon leads to a sharp increase in the thermal stability of the characteristics due to a decrease in the concentration thermo defects. Since the concentration of electrically active atoms of these impurities is $\sim 0.1 \%$ of the total solubility and does not exceed $10^{14} \mathrm{~cm}^{-3}$, and active centers are not formed as a result of the interaction of nickel with oxygen, there is a real possibility to use nickel to obtain thermostable materials. To study the effect of HT(Heat Treatment) on the properties of uncompensated or weakly compensated silicon, nickel was diffused into p-type silicon with $\rho=10 \div 40 \mathrm{Ohm} \cdot \mathrm{cm}$ and n-type with $\rho=10 \div$ $40 \mathrm{Ohm} \cdot \mathrm{cm}$. In this case, the diffusion temperature was chosen so that the concentration of electrically active $\mathrm{Ni}$ atoms was much lower than the initial fine impurities, i.e. The introduction of nickel did not lead to a change in the parameters of the sample.

According to the Hall measurements, as well as the IR absorption and recombination radiation spectra of centers that include nickel atoms, no nickel was detected. PL bandsat 0.861; According to [11], 0.867 and $0.875 \mathrm{eV}$ earlier, which were associated with defects containing $\mathrm{Ni}$ atoms, were manifested both in the heat-treated undoped nickel material and in Sicrystals containing copper impurity. From the analysis of the results obtained for high-purity silicon after nickel diffusion on it (Figure1), the following basic laws can be formulated:

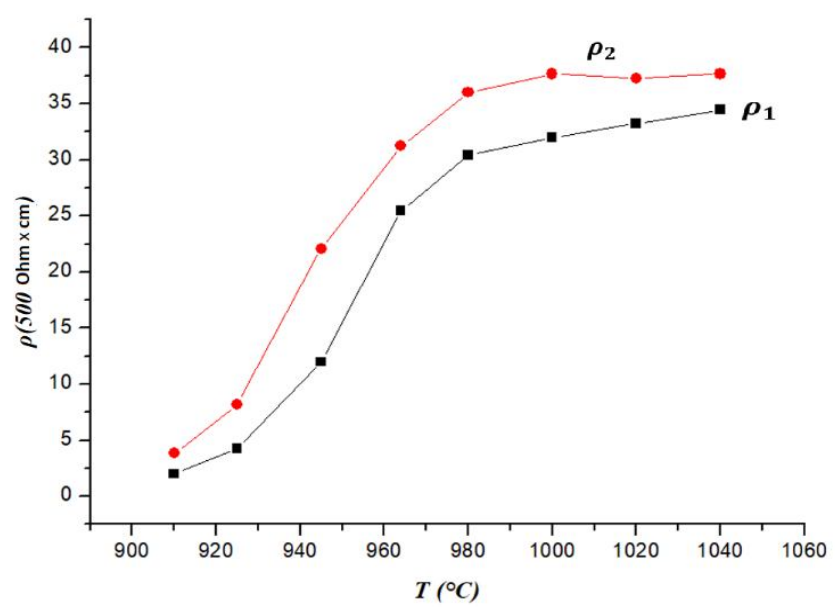

Figure 1: Dependenceofresistivityontemperatureat $\rho_{1}=500$ $\mathrm{kOhm} * \mathrm{sm}, \rho_{2}=1000 \mathrm{kOhm} * \mathrm{sm}$.

- an increase in the specific resistance of the material is observed when the temperature of diffusion annealing is increased, and the degree of compensation is dependent on the axiallocation of the test plate in the ingot, which determines the content of the main background technological impurities $(\mathrm{O}$, C, etc.) init;

- a decrease in the lifetime of non equilibrium charge carriers is observed with an increase in $\mathrm{T}_{\text {dif }}$ : at $\mathrm{T}_{\text {dif }}>960^{\circ} \mathrm{C}, \tau$ decreased by 2-3 times, and the most noticeable decrease in this parameter to $\sim(2-3) \mu \mathrm{c}$ was manifested at temperatures exceeding $1000^{\circ} \mathrm{C}$. An effective sink with respect to rapidly diffusing impurities ( $\mathrm{Au}, \mathrm{Cu}$, etc.) is a nickel film deposited on a silicon surface; the hegering effect is associated with the formation of a Ni and Silayer (Ni-Si) [6],[10], under which there is a layer saturated with interstitial nickel atoms.

Table 1 shows the electrical parameters of silicon obtained before and after alloying with nickel at various temperatures. A significant change in the conductivity of the samples occurs when nickel is introduced into n-silicon with $\rho \sim 10$ Ohm.cm.To obtain samples with different resistivity suptointrinsic, it is necessary to use n-silicon. The introduction of nickel into p-silicon showed that a marked increase in conductivity is observed only in samples with an initial $\rho \sim 60$ $\mathrm{Ohm} \cdot \mathrm{cm}$. The electrical parameters of silicon before and after doping with nickel were determined by the Hall effect method [12].

During long-term heat treatment with $\mathrm{T}_{\mathrm{dif}} \leq 1000^{\circ} \mathrm{C}$, it was not possible to obtain crystals with high specific resistance ( $\rho>5 \cdot 10^{3} \mathrm{Ohm} \cdot \mathrm{cm}$ ) even after a long 24-hour annealing (Table 1). Heating in the temperature range of $1000-1050^{\circ} \mathrm{C}$ led to a significant decrease in $\tau$ to $1-3 \mu$ s and to the degradation of the Hall charge carrier mobility $(\mu \mathrm{H})$ measured at $300 \mathrm{~K}$, which showed an anomalous temperature dependence. This indicates the presence of regions of space charge in diffusion-doped $\mathrm{Si}: \mathrm{Ni}$ crystals at temperatures 
above $1000{ }^{\circ} \mathrm{C}$ associated with macroscopic impurity-defect clusters, which may include $\mathrm{Ni}$ and oxygen atoms.

Heat treatment of crystalline Si:Ni. The experiment showed that during the HT of silicon with nickel in the temperature range $100 \div 920^{\circ} \mathrm{C}$ there are three characteristic sections of the change in the properties of the samples:

1. HT with a duration of up to 50 hours in the temperature range $100 \div 500{ }^{\circ} \mathrm{C}$ does not lead to a significant change in the electrophysical and photoelectric properties of $\mathrm{Si}\langle\mathrm{Ni}\rangle$ samples.

2. HT at a temperature of $500 \div 800^{\circ} \mathrm{C}$ for $10 \div 50$ hours leads to an increase in the concentration of electrically active $\mathrm{Ni}$ atoms in $\mathrm{Si}$, and with a further increase in the TO time, no significant changes are observed.

3. HT above $800 \mathrm{C}$ for $15 \div 20 \mathrm{~min}$. leads to a sharp decrease in the concentration of nickel and the samples acquire practically the properties of the starting material, i.e. The usual decomposition of a supersaturated solid solution occurs.

The proposed method of alloying silicon made it possible to obtain clusters of impurity nickel atoms, due to a more efficient introduction of impurity atoms into silicon and an increase in the diffusion coefficient, as well as the solubility of nickel in silicon, see Figure 2a. In additional low-temperature treatments in the temperature range $550^{\circ} \mathrm{C}$ to $900^{\circ} \mathrm{C}$, the clusters of impurity nickel atoms are ordered in

Table 1:Electrical parameters of silicon before and after nickel alloying

\begin{tabular}{|l|l|l|l|l|l|l|l|}
\hline \multicolumn{2}{|c|}{$\begin{array}{c}\text { Before } \\
\text { diffusion }\end{array}$} & \multicolumn{2}{|c|}{$\begin{array}{c}\text { Diffusion } \\
\text { condition }\end{array}$} & \multicolumn{5}{|c|}{ After diffusion } \\
\hline Type & $\begin{array}{c}\rho \\
{[\text { Ohm }} \\
\mathrm{cm}]\end{array}$ & $\begin{array}{c}\mathrm{T} \\
{\left[{ }^{\circ} \mathrm{C}\right]}\end{array}$ & $\begin{array}{c}\mathrm{t} \\
{[\text { hour }]}\end{array}$ & $\mathrm{Type}$ & $\begin{array}{c}\rho \\
{[\mathrm{Ohm} \cdot} \\
\mathrm{cm}]\end{array}$ & $\begin{array}{c}\mathrm{n} \cdot \mathrm{p} . \mathrm{c} \\
\mathrm{m}^{-3}\end{array}$ & $\begin{array}{c}\mu \\
{\left[\mathrm{cm}^{2} \mathrm{~V}\right.}\end{array}$ \\
\hline $\mathrm{n}$ & 10 & 1250 & 1 & $\mathrm{n}$ & 65 & $\begin{array}{l}7.5 \cdot 10 \\
13\end{array}$ & 1252 \\
\hline $\mathrm{n}$ & 10 & 1200 & 1 & $\mathrm{n}$ & 19.7 & $\begin{array}{l}3.6 \cdot 10 \\
14\end{array}$ & 1372 \\
\hline $\mathrm{n}$ & 10 & 1150 & 1.5 & $\mathrm{n}$ & 9.4 & $\begin{array}{l}4.5 \cdot 10 \\
14\end{array}$ & 1228 \\
\hline $\mathrm{n}$ & 10 & 1100 & 2 & $\mathrm{n}$ & 8.6 & $\begin{array}{l}6.4 \cdot 10 \\
14\end{array}$ & 1209 \\
\hline $\mathrm{n}$ & 10 & 1050 & 2 & $\mathrm{n}$ & 9.1 & $\begin{array}{l}5.6 \cdot 10 \\
14\end{array}$ & 1233 \\
\hline $\mathrm{n}$ & 40 & 1250 & 1.5 & $\mathrm{n}$ & $1 \cdot 10^{5}$ & $\begin{array}{l}4.8 \cdot 10 \\
14\end{array}$ & 2010 \\
\hline $\mathrm{n}$ & 40 & 1150 & 1.5 & $\mathrm{n}$ & 65 & $6 \cdot 10^{13}$ & 1400 \\
\hline $\mathrm{n}$ & 200 & 1250 & 1 & $\mathrm{p}$ & $6 \cdot 10^{4}$ & $9 \cdot 10^{11}$ & 261 \\
\hline $\mathrm{n}$ & 200 & 1200 & 1.5 & $\mathrm{n}$ & $10^{5}$ & $6 \cdot 10^{10}$ & 2017 \\
\hline $\mathrm{n}$ & 200 & 1100 & 1.5 & $\mathrm{n}$ & $3.5 \cdot 10^{2}$ & $\begin{array}{l}1.98 \cdot 1 \\
0^{13}\end{array}$ & 1292 \\
\hline $\mathrm{n}$ & 200 & 1000 & 2 & $\mathrm{n}$ & 220 & $\begin{array}{l}1.93 \cdot 1 \\
0^{13}\end{array}$ & 1468 \\
\hline $\mathrm{p}$ & 10 & 1250 & 1.5 & $\mathrm{p}$ & 11.8 & $\begin{array}{l}2.15 \cdot 1 \\
0^{15}\end{array}$ & 267 \\
\hline $\mathrm{p}$ & 10 & 1100 & 1.5 & $\mathrm{p}$ & 10.9 & $\begin{array}{l}1.95 \cdot 1 \\
0^{15}\end{array}$ & 288 \\
\hline $\mathrm{p}$ & 30 & 1100 & 1.5 & $\mathrm{p}$ & 31 & $5 \cdot 10^{14}$ & 376 \\
\hline
\end{tabular}

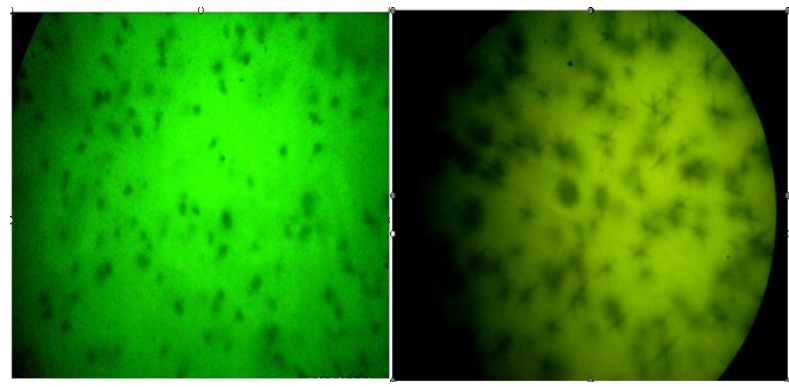

a) nickel atom nanoclusters in silicon

b) ordering of nanoclusters afterlow temperature annealing

Figure 2: Micrographs of the surface of nickel alloyed silicon.

the silicon lattice, as shown in Figure 2b. At the same time, by selecting technological modes, it was possible to ensure self-organized ordering of nickel clusters, which are ordered in the silicon lattice with a certain "organization" throughout the crystal volume. In this way, it has been established that under certain thermodynamic conditions, self-organization of impurity atoms in the semiconductor lattice and their ordering takes place. At the same time, the ability to control the size, composition and ordering of clusters was clearly established. These data indicate the possibility of creating nanoparticles of various types $(2 \mathrm{D}, 1 \mathrm{D}, 0 \mathrm{D})$, both on the surface and in the bulk of the crystal lattice. In $\mathrm{Si}<\mathrm{Ni}>$ samples, two significant features are observed during thermal treatments:

- during prolonged heat treatment in the temperature range $300-500^{\circ} \mathrm{C}$, the electrophysical and photoelectric parameters of the $\mathrm{Si}<\mathrm{Ni}>$ and $\mathrm{Si}<\mathrm{Co}>$ samples do not change, i.e. stable.

- during heat treatment in the temperature range $500 \div 800^{\circ}$ $\mathrm{C}$, an increase in the concentration of electrically active $\mathrm{Ni}$ atoms is observed. Changes in the conductivity and concentration of current carriers in $\mathrm{Si}\langle\mathrm{Ni}\rangle$ samples subjected to $\mathrm{HT}$ at various temperatures showed that compensated $\mathrm{n}-\mathrm{Si}$ $<\mathrm{Ni}\rangle$ samples upon annealing in the range of $600-700{ }^{\circ} \mathrm{C}$ for several hours change the type of conductivity and become hole-like. At the same time, $\mathrm{p}-\mathrm{Si}<\mathrm{Ni}>$ samples become lower resistance.

These results indicate the appearance of additional acceptor levels in the thermal processes of thermal annealing in the lower half of the band gap. Depending on the temperature of thermal annealing, the concentration of electrically active nickel can increase by 1-1.5 orders of magnitude (see Figure 3 ).Experiments show that an increase in the concentration of $\mathrm{Ni}$ atoms during heat treatment is characteristic of $\mathrm{Si}\langle\mathrm{Ni}\rangle, \mathrm{Ni}$ atoms depending on the annealing temperature samples, both dislocation and dislocation-free. The presence of dislocations in samples accelerates the process of increasing the concentration of electrically active atoms of a dopant, but does not affect its maximum value.

From the results of electrical and diffusion studies of $\mathrm{Ni}$ in silicon, it has been unequivocally established that the electrically active $\mathrm{Ni}$ atom is a substitution atom, and the number of such atoms is 0.1 of the total concentration of dissolved atoms. The main part of $\mathrm{Ni}$ atoms is electrically 
neutral and is located in the interstices of the crystal lattice. The results of HT can be explained on the basis of the assumption that during low-temperature treatments, intensive migration of interstitial $\mathrm{Ni}$ atoms to decay centers begins, which is accompanied by a simultaneous transition of nickel atoms from the interstitial site to the lattice sites and vice versa $\mathrm{N}_{\mathrm{i}}+\mathrm{V} \rightrightarrows \mathrm{N}_{\mathrm{s}}$. Since the concentration of nickel atoms in the

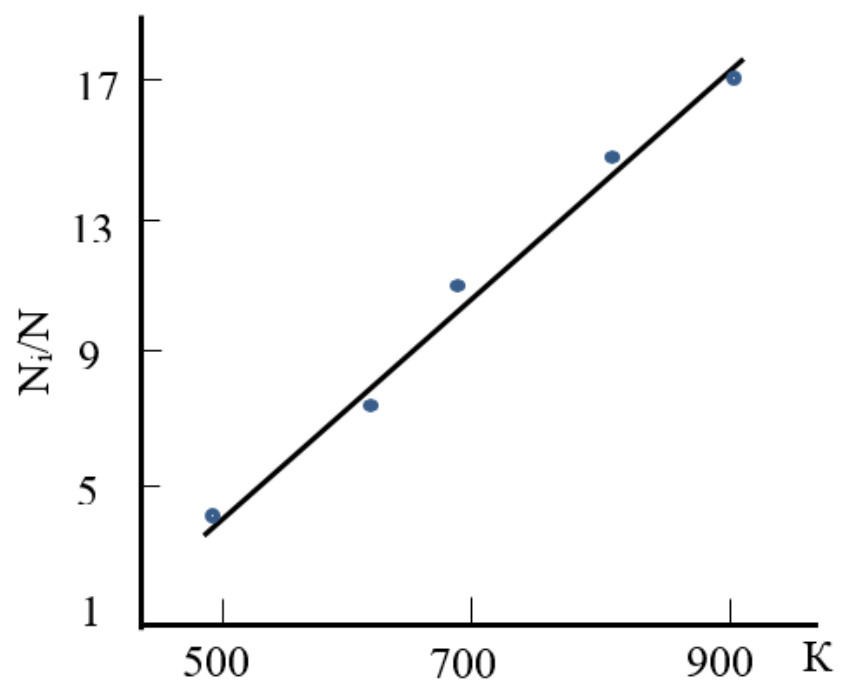

Figure 3: The relative change in the electroactive concentration.

internodes is much higher than at the lattice sites, the transition from the internodes to the site will be predominant in the initial stages of heat treatment. The intensity of such a transition is determined by the rate of diffusion flux of vacancies from the surface of the sample and the rate of generation of vacancies by internal sources in the volume.

Table 2: Electrical characteristics of compensated silicon

\begin{tabular}{|c|c|c|c|}
\hline Patterns & Type & $\rho[$ Ohm $\cdot \mathrm{cm}]$ & $\mu\left[\mathrm{cm}^{2} \mathrm{~V}^{-1} \mathrm{~s}^{-1]}\right.$ \\
\hline $\mathrm{Si}<\mathrm{Mn}>$ & $\mathrm{n}$ & $4.6 \cdot 10^{2}$ & 1087 \\
\hline $\mathrm{Si}<\mathrm{Mn}>$ & $\mathrm{n}$ & $3.4 \cdot 10^{3}$ & 1030 \\
\hline $\mathrm{Si}<\mathrm{Mn}>$ & $\mathrm{n}$ & $4 \cdot 10^{4}$ & 880 \\
\hline $\mathrm{Si}<\mathrm{Mn}>$ & $\mathrm{n}$ & $2 \cdot 10^{5}$ & 620 \\
\hline $\mathrm{Si}<\mathrm{Mn}>$ & $\mathrm{p}$ & $1.5 \cdot 10^{4}$ & 116 \\
\hline $\mathrm{Si}<\mathrm{Ni}>$ & $\mathrm{n}$ & $3.3 \cdot 10^{3}$ & 1206 \\
\hline $\mathrm{Si}<\mathrm{Ni}>$ & $\mathrm{n}$ & $10^{5}$ & 1017 \\
\hline $\mathrm{Si}<\mathrm{Co}>$ & $\mathrm{n}$ & $8 \cdot 10^{2}$ & 1270 \\
\hline $\mathrm{Si}<\mathrm{Co}>$ & $\mathrm{n}$ & $8.3 \cdot 10^{2}$ & 1120 \\
\hline $\mathrm{Si}<\mathrm{Fe}>$ & $\mathrm{n}$ & $6.4 \cdot 10^{3}$ & 1000 \\
\hline $\mathrm{Si}<\mathrm{Fe}>$ & $\mathrm{n}$ & $3 \cdot 10^{4}$ & 910 \\
\hline
\end{tabular}

From a comparison of the characteristics of $\mathrm{Si}$ doped with $\mathrm{Ni}$ and with other impurities $\mathrm{Mn}, \mathrm{Fe}$, and Co (see Table 2), it follows that a significant change is observed in the samples $\mathrm{Si}$ $\langle\mathrm{Mn}\rangle$ and $\mathrm{Si}\langle\mathrm{Fe}\rangle$, in the samples $\mathrm{Si}\langle\mathrm{Ni}\rangle$ and $\mathrm{Si}\langle\mathrm{Co}\rangle$ the change in mobility is weaker, which may be due to a small concentration of electrically active charged $\mathrm{Ni}$ and $\mathrm{Co}$ atoms in Si compared with Mn and Fe. It is known that the electrical parameters of materials (concentration of current carriers and type of conductivity) are determined by the position of the Fermi levels. The position of the Fermi level depends on the energy spectrum of impurities, its concentration, and also the temperature of the material. Therefore, to control the electrical parameters of silicon when introducing a compensating impurity, it is necessary to know how the position of the Fermi level changes depending on the concentration of the introduced impurity at a given temperature.

The concentration, number, nature, and even the ionization energy of impurity levels apparently depend significantly on the conditions of diffusion doping, as well as on the parameters of the starting material and the degree of compensation of the material. Therefore, to develop a technology for producing compensated silicon with specified parameters and reproducible electrophysical properties, it is necessary to establish the laws of the dependence of energy levels on the conditions of diffusion alloying and the parameters of the starting materials. For nickel and cobalt, the ratio of the concentration of electrically active atoms to the total concentration of impurity atoms is $10-4$, shown by authors of [13]-[15]. Such a significant difference between the solubility and the concentration of electrically active atoms can be explained if we assume that due to the large diffusion coefficient during cooling, the bulk of the atoms leave the solution [15].

\section{DISCUSSION}

A more detailed study of these impurities at various cooling rates of deg / s showed that the concentration of electrically active atoms in them is practically independent of the cooling rate. Studies of the annealing time on the properties of compensated silicon showed that the necessary time for uniform saturation of samples at temperatures above $1000^{\circ} \mathrm{C}$ and a coating thickness of $1 \mathrm{~mm}$ is $30-90$ minutes. We found that conducting diffusion annealing only at optimal temperatures ensures the production of compensated silicon with stable parameters [16], [17].

However, experimental studies show that samples with a maximum concentration of electrically active atoms uniformly doped with stable parameters of the energy levels of impurities can be obtained with an annealing time of $1.5-2$ hours depending on the annealing temperature (1000 - $1350^{\circ}$ C). With a further increase in the annealing time, a saturation of the concentration of electrically active impurity atoms is observed. Studies have shown that the position, nature and concentration of electrical levels of impurities substantially depend on the conditions of diffusion annealing, the initial concentration of impurities, and also the degree of compensation. Therefore, it is required for each impurity to experimentally determine the optimal conditions for diffusion annealing, which provide a compensated material with stable and reproducible parameters. 
Studies of the effect of annealing conditions and the parameters of the initial material on the properties of compensated silicon made it possible to develop a technology for producing $\mathrm{n}$ - and $\mathrm{p}$-type silicon crystals with specified parameters. It is as follows:

-diffusion of nickel is carried out from a nickel layer deposited on a chemically etched silicon surface in an inert gas atmosphere or in air;

-the cooling rate after diffusion should be no more than 100 $120\left[{ }^{\circ} \mathrm{C} / \mathrm{s}\right]$, the optimal diffusion temperature of $\mathrm{Ni}$ is $1100^{\circ}$ C. and diffusion annealing time 1.5 - 2 hours;

- as the starting material, it is necessary to use p-type silicon with a specific resistance of $40-60 \mathrm{Ohm} \cdot \mathrm{cm}$ for $\mathrm{Ni}$;

- the above diffusion conditions are quite applicable for samples with a thickness of up to $1 \mathrm{~mm}$, area $S=2 \mathrm{~cm} 2$. After diffusion, it is necessary to remove a layer with a thickness of $\sim 4050 \mu \mathrm{m}$ from the surface;

- these technology conditions are also suitable for obtaining compensated samples with studied impurities by ion implantation. In this case, the ion energy should be no more than $40-60 \mathrm{KeV}$.

Nickel atoms in the site of the silicon lattice must be a double acceptor. Nickel, in fact, creates two acceptor levels, the concentration and electron capture cross section to these levels show that they are associated with the nickel substitution atom in silicon. As shown, the concentration of nickel atoms in the nodes is $0.01-0.05 \%$ of the total solubility. Unlike the interstitial atom of manganese and iron, the interstitial nickel does not create a donor level [18],[19].

\section{CONCLUSION}

To sum up, the results obtained indicate that during diffusion, the introduction of nickel impurities into silicon can be used as compensating for $\mathrm{n}$-Si. Experimental studies show that samples with a maximum concentration of electrically active atoms uniformly doped with stable parameters of the energy levels of impurities can be obtained with an annealing time of 1.5 - 2 hours depending on the annealing temperature (1000 $1350^{\circ} \mathrm{C}$ ). The upper temperature limit is determined by the effective transformations in the $\mathrm{Si}-\mathrm{Ni}$ system, leading to a "loss" of the surface nickel gettering properties relative to the background technological impurities: the lower decay of the supersaturated Ni solid solution in silicon, which occurs in the temperature range $600-700^{\circ} \mathrm{C}$. Furthermore, investigations of thermal defect formation showed that nickel impurity only indirectly participates in the reactions of introducing thermo donors, the suppression of the generation of which is explained by the interaction of nickel and oxygen atoms, which partially excludes the last of the corresponding processes. The studies showed that the position, nature and concentration of electrical levels of impurities substantially depend on the conditions of diffusion annealing, the initial concentration of impurities, and also the degree of compensation.

\section{ACKNOWLEDGEMENT}

The authors wish to thank Research Institute of Semiconductors and Microelectronics under National University of Uzbekistan for providing with their lab.

\section{REFERENCES}

1. Properties of silicon doped with nickel impurity by diffusion, Reports of BSUIR №8, pp.38, 2008.

2. B. Gao, S. Nakano, K. Kakimoto. "Influence of reaction between silica crucible and graphite susceptor on impurities of multicrystalline silicon in a unidirectional solidification furnace", J. Cryst. Growth 314: pp. 239, 2011.

https://doi.org/10.1016/j.jcrysgro.2010.12.006

3. SmirnovaZh.V., Cherney O.T, "Laser alloying technology when changing the processing speed", International Journal of Emerging Trends in Engineering Research, Vol. 8. No. 4, pp. 1196-1198, 2020.

https://doi.org/10.30534/ijeter/2020/40842020

4. EkoJulianto, WaluyoAdiSiswanto, Marwan Effendy, "Characteristics of Temperature changes and Stress of Float Glass under Heat Radiation", International Journal of Emerging Trends in Engineering Research, Vol. 7. No. 9, pp. 228-233, 2019.

https://doi.org/10.30534/ijeter/2019/03792019

5. Zhang Jian, Wei-zhen B.A., Chen Zhao-yang, ConfXinyun, Tao Ming-de, Bahadirhanov M.K. Highly compensated $\mathrm{Si}$ Light-SensititiveCharacterstic, Electronic compensated materials, Vol-23, №3.pp.20-22, 2004.

6. V.M. Talanin, I.E. Talanin, The microdefect structure of semiconductor silicon, IzvestiyaVUZov, Mater. ElektronnoyTekhniki 4, pp. 4-15, 2002(in Russian).

7. D.V. Velichko, V.G. Rubanov, Semiconductor Devices and Appliances, V. G. Shukhova Publishing house $B S T U$, Belgorod, 2006, (in Russian).

8. B. P. Korolkov, A.N. Yurkov, A.R. Mikertumyants. Obtaining nickel silicides by burning a metal film into a polysilicon film, Journal of Applied Physics No. 3, 1999.

9. Y. Pratapa Reddy, K. L Narayana, M. Kedar Mallik, "Electro-chemical behaviour of different metals in Sodium Chloride solution", International Journal of Emerging Trends in Engineering Research, Vol. 7. No. 11, pp. 715-719, 2019. https://doi.org/10.30534/ijeter/2019/507112019

10. H. Fujimori, H. Matsushita, I. Oose and T. Okabe, Depth effect of the morphology change induced by hydrogen annealing of grown-in defects in silicon, Journal of The Electrochemical Society 147, pp 3508, 2000. https://doi.org/10.1149/1.1393928

11. A.L. Dolgiy, S.L. Prischepa, V.A. Petrovich, V.P. Bondarenko. Features of electrochemical deposition of nickel into mesoporous silicon, BSUIR reports, No. 1 pp.63-66, 2012.

12. T. R. Mchedlidze and I. Yonenaga. Hall effect in anisotropic SixGe1-x polycrystals, Japanese Journal of Applied Physics, Part 1 Vol 35, pp. 652, 1996. 
13. Zikrillaev N.F., Nasriddinov S.S., Ayupov K.S. Chaos and self-organization in highly compensated silicon, Republican scientific and technical conference "Istiklol", Moscow-Navoi, pp. 177-179, 2007.

14. Egamberdiev B.E., Valiev S.A., Nasriddinov S.S. Development of a new diffusion doping method for the formation of nanoclusters of impurity nickel atoms, Materials of the scientific-practical conference,Karshi, pp. 40-42, 2012.

15. Ayupov K.S. Egamberdiev B.E., Nasriddinov S.S. Temperature and magnetic field sensors based on silicon with nanoclusters of manganese and nickel atoms,Nizhny Novgorod Abstracts, pp.187, 2010.

16. Nasriddinov S.S. Technology for obtaining a temperature sensor with nanoclusters of nickel atoms, Nanoelectronic Physics. Kiev, Volume 5, pp.3-10, 2013.

17. Yuanzhi Chen, Dong-Liang Peng, Dongxing Lin and Xiaohua Luo, Preparation and magnetic properties of nickel nanoparticles via the thermal decomposition of nickel organometallic precursor in alkylamines, Nanotechnology 18, 505703 , pp.6, 2007. https://doi.org/10.1088/0957-4484/18/50/505703

18. G. H. Gilmer, T. Diaz de la Rubia, D. M. Stock and M. Jaraiz, Diffusion and interactions of point-defects in silicon-Molecular-dynamics simulations, Nuclear Instruments and Methods in Physics Research Section B: Beam Interactions with Materials and Atoms 102, pp. 247, 1995. https://doi.org/10.1016/0168-583X(95)80150-K

19. Egamberdiev B.E.,Valiev S.A., Nasriddinov S.S. Development of a new diffusion doping method for the formation of nanoclusters of impurity nickel atoms, Materials of the scientific-practical conference, Karshi, pp. 40-42, 2012. 